\title{
THE ABNORMAL CRYSTALLIZATION OF IEAD AZIDE BY PROTECTIVE COLLOIDS
}

BY

\section{A. G. LOWNDES}

Lead azide $\mathrm{PbN}_{6}$ has been known for some years past to possess all the essential properties of a serviceable initiator of detonation. Both its preparation and manufacture are very easily carried out, all that is necessary being to add a solution of sodium azide to an equivalent quantity of either lead acetate or lead nitrate. In the manufacturing process the acetate is usually employed when lead azide is formed according to the following equation :-

$$
\mathrm{Pb}\left(\mathrm{CH}_{3} \mathrm{COO}\right)_{2}+2 \mathrm{NaN}_{3}=\mathrm{PbN}_{6}+2 \mathrm{CH}_{3} \mathrm{COONa} \text {. }
$$

In the laboratory the azide is prepared by running in equivalent solutions of sodium azide and lead nitrate from two burettes into a suitable receiver containing a little water.

Now, the history of preparation and also of the manufacture of lead azide has been a very checkered one. Explosions have been frequent and no very satisfactory cause has been found for them. It has been generally agreed, however, that these explosions are caused by the fracture of large crystals and, although I have reason to doubt this statement, the problem was at the time to produce the azide in such a way that large crystals, and also crystals that were likely to fracture, should not be formed. This problem was at the time being tackled by the research department of Nobel's Explosion Co., Ardeer Factory, Stenenston, Ayrshire, N.B., where I was employed at the time doing microscopic work.

Any one who is familiar with microchemical analysis knows that the bête noir of all such work is the presence of the slightest trace of a colloid on the microscopic slide which prevents the formation of the normal crystals by which the particular reaction is recognised. On hearing, therefore, of the azide problem, I suggested that the water of the receiver should be replaced by a $\frac{1}{2}$ per cent. solution of gelatin or dextrine. This was accordingly done by the Assistant Manager of Research, Dr. Weir.

The effect of adding the colloid can be seen by reference to the photomicrographs.

Fig. 1 represents a normal manufactured sample, and it will be seen to consist of large partially formed crystals which belong to the Rhombic system. These crystals are really far more solid than they appear, the thickness being considerable.

Fig. 2 simply represents one of these crystals under higher magnification.

H.g. 3 represents a laboratory preparation and shows very perfect crystals, one of which shows a very characteristic twin.

Fig. 4 represents a highly magnified crystal, the twinning of which has given rise to radiating appearance. This kind of crystal was supposed to be the highly sensitive one as it is very liable to fracture on being compressed. 


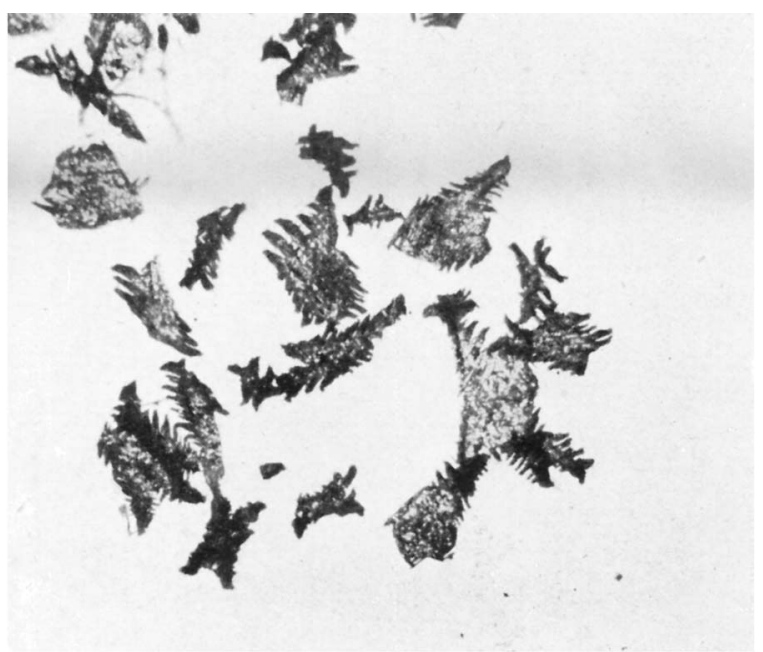

FIa. 1.-Normal manufactured sample. Magnification 50 diam.

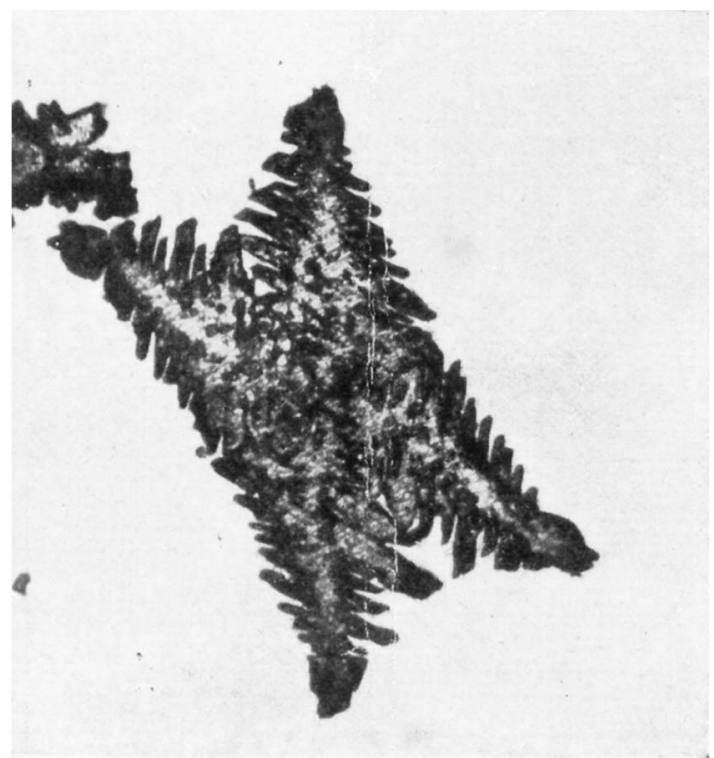

Frg. 2.-Normal manufactured azide. Magnification 500 diam. 


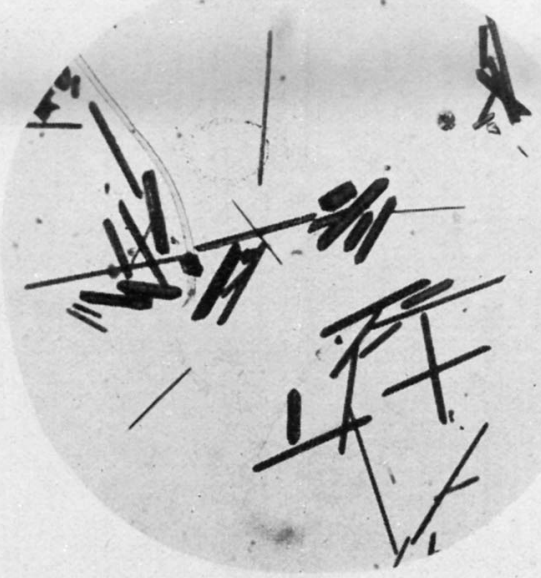

Fig. 3.-Laboratory preparation. Magnification 50 diam.

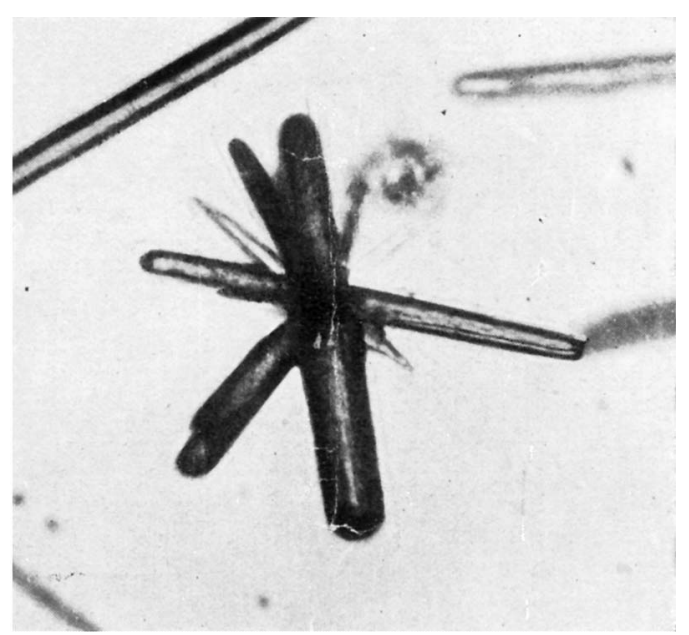

Fit. 4.-Laboratory preparation. Magnification 500 diam. 


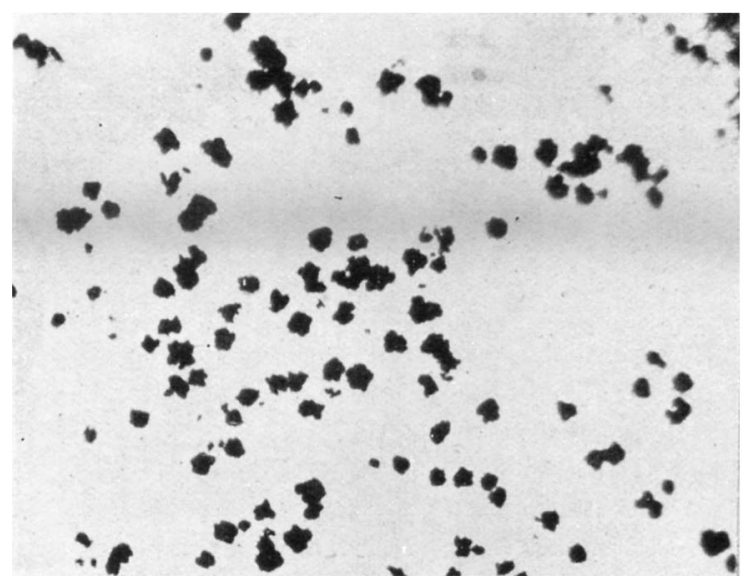

Fig. 5.-Magnification 50 diam.

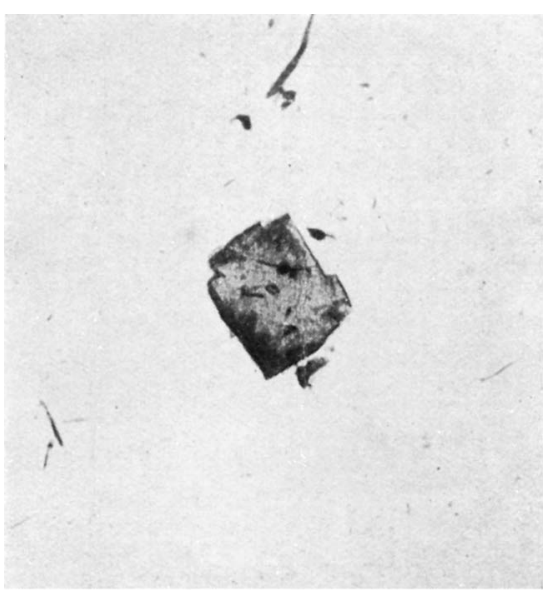

Fig. 6.-Magnification 50 diam.

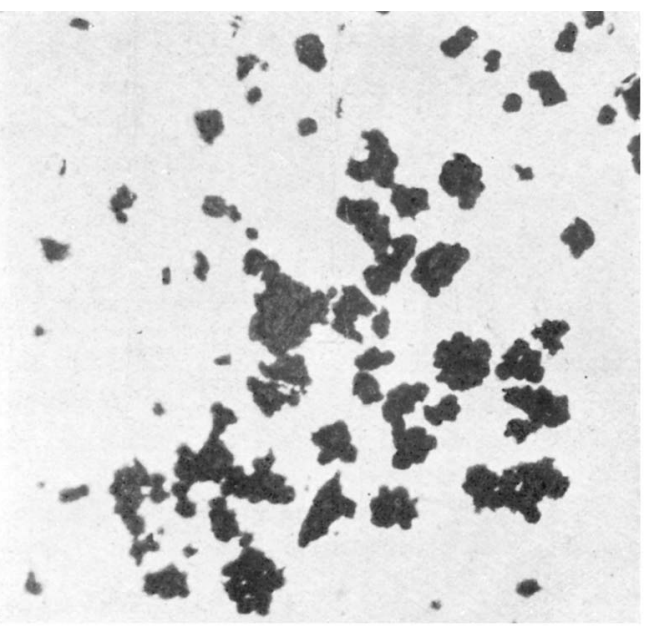

FIa. 7.-Magnification 50 diam. 


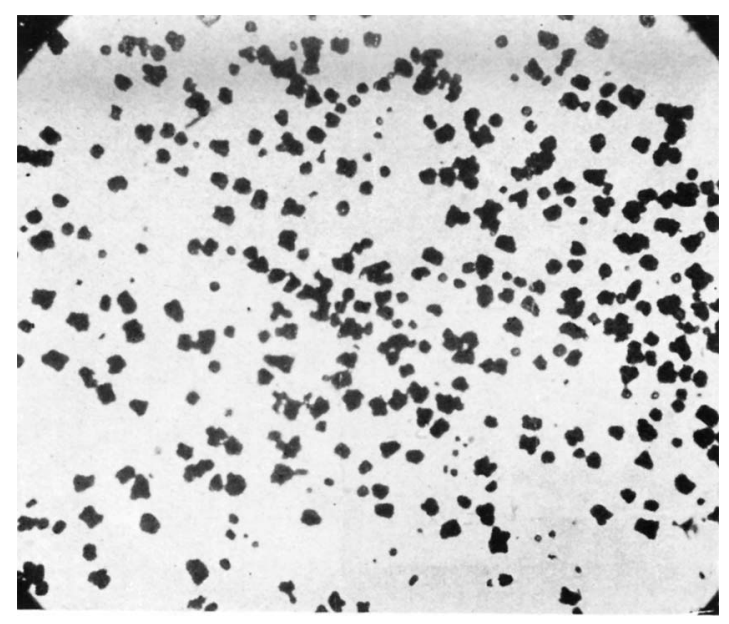

Fra. 8,-Magnification 50 diam.

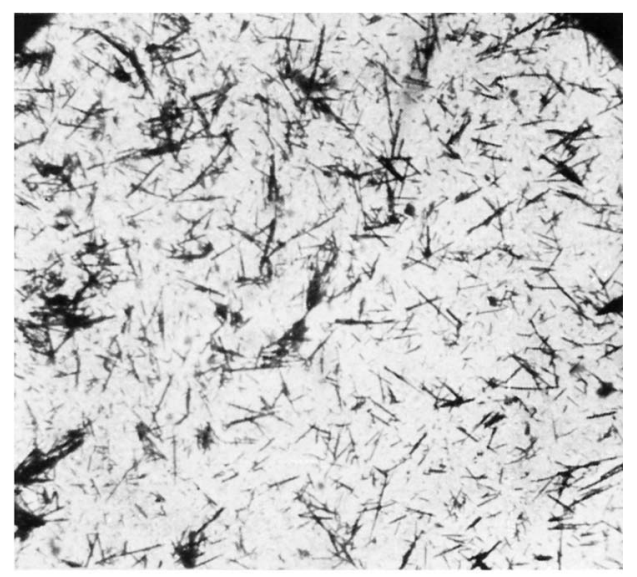

FIG 9.-Magnification 50 diam. 
Figures 5, 7 and 8 represent the result of adding a colloid to the receiver solution. The products are seen to consist of rounded aggregates with little resemblance to the original crystals.

Fig. 9 represents the result of adding ferric chloride to the receiver solution. It will be noticed that the product is certainly crystalline and from a manufacturing point of view is a quite unsuitable product.

Fig. 6 represents a peculiar crystal that was formed when the receiver solution contained 0.5 per cent. ferric chloride acidified with glacial acetic acid.

It probably consists of a basic ferric azide as microchemical analysis showed it to contain iron.

The crystal was also shown to be insoluble in nitric acid. Further analysis was not carried out since it involved the separation by mechanical means of the crystals on the microscopic slide.

Not only was it essential to prevent normal crystallisation but it was necessary to produce the azide in a homogeneous form, and also in a form that would possess a low angle of flow in order to comply with the necessary conditions of filtration and the further loading of detonators. The necessary conditions were found for producing large quantities of the azide represented in Fig. 8. 